\title{
Length of residence and obesity among immigrants in Spain
}

\author{
Juan L Gutiérrez-Fisac 1,2,* Ana Marín-Guerrero ${ }^{3}$, Enrique Regidor ${ }^{4}$, \\ Pilar Guallar-Castillón ${ }^{1,2}$, Jose R Banegas ${ }^{1,2}$ and Fernando Rodríguez-Artalejo ${ }^{1,2}$ \\ 'Department of Preventive Medicine and Public Health, School of Medicine, Universidad Autónoma de Madrid, \\ C/Arzobispo Morcillo s/n, E-28029 Madrid, Spain: ${ }^{2}$ CIBER de Epidemiología y Salud Pública (CIBERESP), \\ Barcelona, Spain: ${ }^{3}$ Unidad de Medicina Preventiva, Hospital Nuestra Señora del Prado, Talavera de la Reina, \\ Spain: ${ }^{4}$ Department of Preventive Medicine and Public Health, School of Medicine, Universidad Complutense de \\ Madrid, Madrid, Spain
}

Submitted 9 February 2009: Accepted 1 November 2009: First published online 3 December 2009

\begin{abstract}
Objective: Various studies in the USA and Canada have consistently shown a positive association between length of residence of immigrants and obesity. Studies in European countries have obtained less consistent results. The present work assesses the influence of length of residence on the frequency of obesity in immigrants in the city of Madrid, Spain.

Design: We studied a sample of 7155 persons aged 18 years and over residing in the city of Madrid, who were was surveyed between November 2004 and May 2005. Information was collected on immigrant status (country of birth), length of residence in Spain, obesity, sociodemographic characteristics and lifestyle.

Results: Compared with the Spanish population, the odds for obesity in the immigrant population by length of residence was less than one in all groups, becoming closer to one with increasing time of residence $(\mathrm{OR}=0 \cdot 67,0.73$ and $0 \cdot 81$ for immigrants with less than 2, 2-4 and 5-9 years of residence in Spain, respectively), up to 10 or more years of residence, when it declined (OR $=0 \cdot 69$ ). The magnitude of this association was considerably reduced after adjusting for sociodemographic variables and for perceived health, but was not further modified after adjusting for lifestyle variables.

Conclusions: Length of residence of immigrants in the city of Madrid is not associated with the frequency of obesity. It is possible that the circumstances immigrants encounter after arriving in Spain do not involve an overexposure to factors favouring obesity, relative to those they bring with them.
\end{abstract}

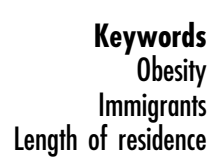

Several studies have tested the hypothesis that over time immigrants assimilate certain attitudes and behaviours of the host country's population related to diet, physical activity and other lesser known determinants that favour the occurrence of obesity. Studies in the USA, both in specific populations such as Hispanics ${ }^{(1,2)}$, Latina women $^{(3-5)}$ and immigrants of Asian origin ${ }^{(6)}$ and in the general immigrant population ${ }^{(7,8)}$, have consistently shown a positive association between length of residence and frequency of obesity. Similar studies have shown the same effect in immigrants in Canada ${ }^{(9-11)}$. Other US studies using immigrants' generational status rather than length of residence have shown that obesity is more frequent in successive generations of immigrants than in the first generation that came to the USA ${ }^{(12,13)}$.

Investigations in European countries are less numerous, and their results differ from those of the foregoing studies. Lindström and Sundquist ${ }^{(14)}$ observed a weak effect of length of residence on obesity in immigrants in
Sweden, which was seen only in immigrants from certain countries. The Malmö Diet and Cancer Study showed a negative effect of length of residence in Sweden on immigrants from different parts of Europe on central obesity, whereas a positive effect on percentage of body fat was observed only in women ${ }^{(15)}$. A study among immigrants of Turkish and Moroccan origin in the city of Amsterdam showed a positive effect of length of residence on obesity in Moroccan immigrants but not in those from Turkey ${ }^{(16)}$.

The different results of studies in North America and European countries suggest that the effect of length of residence on obesity may be subject to intercultural variability. This effect may be quite different in countries of Southern Europe, where the immigration phenomenon is much more recent and where the economic, social and physical environment could have a different effect on the frequency of obesity. There are no studies of this subject in Southern European countries like Spain, where immigration 
in recent years has been the highest in the European Union and one of the highest in the world ${ }^{(17)}$ and where some frequent lifestyles may promote obesity ${ }^{(18)}$. For this reason, we undertook a study of the influence of length of residence on the frequency of obesity in immigrants in the city of Madrid, Spain. Madrid is a city in Southern Europe with a high rate of physical inactivity among the adult population, which may contribute to obesity.

\section{Materials and methods}

The data for the present study were obtained from the 2005 Health Survey in the city of Madrid, made in the non-institutionalised resident population. Two-stage cluster sampling was carried out. In the first stage, census sections were chosen with a probability proportional to the size of the population residing in each section. In the second stage, individuals were selected with equal probability. The selection of the person to be interviewed in each section was made by simple random sampling. Data were collected between November 2004 and May 2005. A total of 7341 interviews were conducted in persons aged 16 years and over. The present analysis was made only in individuals aged 18 years and over. The final sample analysed was composed of 7155 individuals.

The dependent variable was obesity, estimated from BMI calculated as weight in kilograms divided by the square of height in metres $\left(\mathrm{kg} / \mathrm{m}^{2}\right)$. Weight and height were self-reported and obtained by the following questions: 'About how much do you weigh without shoes or clothes?' and 'About how tall are you without shoes?' Obesity was defined as BMI $\geq 30 \mathrm{~kg} / \mathrm{m}^{2}$.

Immigrant status was defined by place of birth. Those born outside Spain were considered immigrants and were classified by country of birth into four groups: Western countries (USA, Canada, Western Europe), Eastern Europe, Latin America (South America and Central America) and Other (Africa and Asia). For immigrants, length of residence in Spain was classified into the following categories: $<2$ years, $2-4$ years, $5-9$ years and $\geq 10$ years.

In addition to age and sex, several confounding factors were considered. Self-reported health was classified as good (good or very good) or poor (average, poor or very poor). Social class of the primary household earner was classified according to the National Classification of Occupations into the following categories: class I, managers and professionals with a university degree; class II, administrative employees and support professionals/selfemployed workers/supervisors of manual workers; class III, skilled manual workers; class IV, semi-skilled manual workers; class V, unskilled manual workers; and class X, others. Marital status was classified as married (married or living with a partner) and unmarried (single, separated, divorced or widowed). For the lifestyle variables, smoking was classified as non-smoker (does not smoke and has never been a regular smoker), smoker (smokes daily and smokes but not daily) and ex-smoker (does not currently smoke but did so in the past). Alcohol consumption was classified as non-drinker (does not consume alcohol), occasional drinker (consumes once or less per week), frequent drinker (consumes alcohol on two to five days per week) and daily drinker (consumes alcohol every day of the week). With the available information about diet, we defined the variable daily consumption of fruits and vegetables (yes/no). Finally, based on leisuretime physical activity, individuals were classified as sedentary (does not do any physical activity) or active (does some type of physical activity occasionally or several times per week or month).

The association between obesity and length of residence was measured by the odds ratio and its $95 \%$ confidence interval obtained from logistic regression models. Three types of models were fitted, using the Spanish population as the reference group: a first crude model; a second model that included age, sex, social class and self-perceived health; and a third model that also considered physical activity, fruit and vegetable consumption, smoking and alcohol intake.

Statistical significance was set at two-sided $P<0 \cdot 05$. Analyses were performed using the SPSS statistical software package version $13 \cdot 0$ (SPSS Inc., Chicago, IL, USA).

\section{Results}

Figure 1 shows the prevalence of obesity in the Spanish population and in the immigrant population by length of residence in Spain. The frequency of obesity was higher in the Spanish population (11.9\%) than in the immigrant population, among whom the prevalence of obesity was $8.1 \%$ in those who had been in Spain for less than 2 years, $8.9 \%$ in those with $2-4$ years' residence and $9.7 \%$ in those with 5-9 years' residence. This increasing trend (which was statistically significant up to that time) was interrupted at 10 or more years' residence, when the prevalence dropped to $8 \cdot 6 \%$.

Table 1 shows the characteristics of the Spanish population and the immigrant population according to

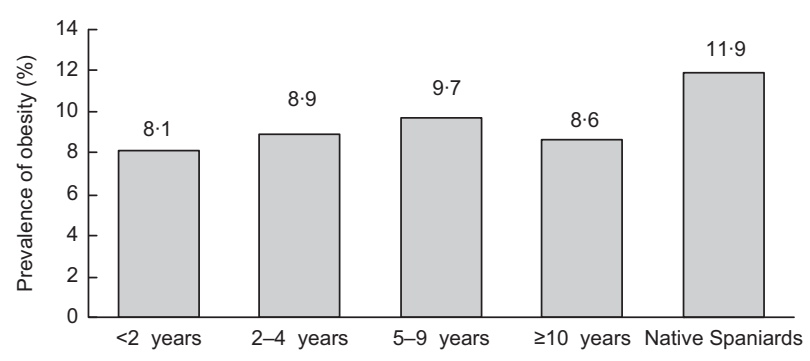

Fig. 1 Prevalence of obesity in the Spanish population and the immigrant population by length of residence in Spain; sample comprised 7155 persons aged 18 years and over residing in the city of Madrid, who were was surveyed between November 2004 and May 2005 
Table 1 Characteristics of the Spanish population and the immigrant population by length of residence in Spain; sample comprised 7155 persons aged 18 years and over residing in the city of Madrid, who were was surveyed between November 2004 and May 2005

\begin{tabular}{|c|c|c|c|c|c|c|}
\hline & \multirow[b]{3}{*}{ Spanish population } & \multicolumn{5}{|c|}{ Immigrant population } \\
\hline & & \multicolumn{4}{|c|}{ Length of residence } & \multirow[b]{2}{*}{$P$ for trend ${ }^{*}$} \\
\hline & & $<2$ years & $2-4$ years & $5-9$ years & $\geq 10$ years & \\
\hline$n$ & 6222 & 62 & 314 & 279 & 278 & \\
\hline$\%$ Aged $18-24$ years & $9 \cdot 0$ & $25 \cdot 8$ & $15 \cdot 0$ & $6 \cdot 5$ & $5 \cdot 4$ & $<0.001$ \\
\hline$\%$ Aged $18-44$ years & $42 \cdot 9$ & $87 \cdot 1$ & $85 \cdot 0$ & $84 \cdot 6$ & $54 \cdot 7$ & $<0.001$ \\
\hline$\%$ Men & $44 \cdot 9$ & $54 \cdot 8$ & $50 \cdot 6$ & $47 \cdot 7$ & $44 \cdot 2$ & $<0.05$ \\
\hline$\%$ Good perceived health & $74 \cdot 5$ & $90 \cdot 3$ & $86 \cdot 6$ & $85 \cdot 3$ & $81 \cdot 3$ & NS \\
\hline \% Social class I-II & $32 \cdot 2$ & $18 \cdot 0$ & $9 \cdot 9$ & $15 \cdot 1$ & $35 \cdot 1$ & $<0.001$ \\
\hline$\%$ Married & $59 \cdot 5$ & $48 \cdot 4$ & $61 \cdot 5$ & $67 \cdot 7$ & $64 \cdot 7$ & NS \\
\hline$\%$ Daily fruit and vegetable consumption & $34 \cdot 4$ & $33 \cdot 9$ & $28 \cdot 0$ & $24 \cdot 5$ & $32 \cdot 4$ & NS \\
\hline$\%$ Sedentary & $37 \cdot 0$ & $45 \cdot 9$ & $46 \cdot 6$ & $42 \cdot 0$ & $33 \cdot 9$ & $<0.001$ \\
\hline$\%$ Non-drinkers & $49 \cdot 7$ & $53 \cdot 2$ & $43 \cdot 5$ & $43 \cdot 4$ & $46 \cdot 8$ & NS \\
\hline$\%$ Daily drinkers & $16 \cdot 3$ & $3 \cdot 2$ & $11 \cdot 5$ & $11 \cdot 8$ & $22 \cdot 3$ & $<0.001$ \\
\hline \% Smokers & $27 \cdot 4$ & $30 \cdot 6$ & $28 \cdot 7$ & $23 \cdot 3$ & $24 \cdot 5$ & NS \\
\hline
\end{tabular}

${ }^{*}$ Trend throughout time of residence in Spain.

length of residence for the main independent variables considered. Compared with the Spanish population, the immigrant population was younger, with a higher percentage of men and persons with good self-perceived health, less sedentary and had a lower percentage of daily drinkers. The percentage of the population in social class I-II was higher in the Spanish population. Among the immigrants, increasing length of residence was associated with a significant decrease in the percentage of the young population, men and sedentary people, and with an increase in the percentage of immigrants in social class I-II and of those who were daily drinkers.

Table 2 shows the percentage of obese persons in the whole sample as a function of the independent variables considered. The frequency of obesity increased with age, from $3 \cdot 5 \%$ in persons aged $18-24$ years to $17 \cdot 9 \%$ in those over 64 years; it was higher in men $(12 \cdot 2 \%)$ than in women $(11.0 \%)$, in those who were married $(13.5 \%)$ than in the unmarried $(8.6 \%)$, and in those with poor selfperceived health $(18.5 \%)$ than in those who reported good health (9.3\%). Obesity was $14.9 \%$ among sedentary individuals and $9 \cdot 5 \%$ among those who were active. The percentage of obese persons was higher in those who abstained from alcohol $(13 \cdot 1 \%)$ and in daily drinkers $(12 \cdot 6 \%)$ than in occasional $(8 \cdot 3 \%)$ and frequent drinkers $(9.5 \%)$, and lower in smokers $(9.4 \%)$ than in nonsmokers $(11.9 \%)$ or ex-smokers (13.9\%). The percentage of obesity did not vary by daily consumption of fruits and vegetables.

Table 3 presents the logistic regression models for obesity in the immigrant population as a whole and by length of residence in comparison to the Spanish population. Overall, the immigrant population had a lower frequency of obesity $(\mathrm{OR}=0.74 ; 95 \% \mathrm{CI} 0 \cdot 58,0 \cdot 94)$ than the Spanish population. The magnitude of this difference was greatly reduced and lost statistical significance after adjusting for age, sex, social class and perceived health
Table 2 Number of subjects and percentage of obese persons $\left(\mathrm{BMI} \geq 30 \mathrm{~kg} / \mathrm{m}^{2}\right)$ by sociodemographic and lifestyle variables; sample comprised 7155 persons aged 18 years and over residing in the city of Madrid, who were was surveyed between November 2004 and May 2005

\begin{tabular}{|c|c|c|}
\hline & $n$ & $\%$ Obese \\
\hline \multicolumn{3}{|l|}{ Age (years) } \\
\hline $18-24$ & 658 & $3 \cdot 5$ \\
\hline $25-44$ & 2718 & $7 \cdot 3$ \\
\hline $45-64$ & 2156 & $14 \cdot 5$ \\
\hline$\geq 65$ years & 1623 & $17 \cdot 9$ \\
\hline \multicolumn{3}{|l|}{ Sex } \\
\hline Male & 3245 & $12 \cdot 2$ \\
\hline Female & 3910 & $11 \cdot 0$ \\
\hline \multicolumn{3}{|l|}{ Perceived health } \\
\hline Good & 5411 & $9 \cdot 3$ \\
\hline Poor & 1726 & $18 \cdot 5$ \\
\hline \multicolumn{3}{|l|}{ Social class } \\
\hline$|-| \mid$ & 2168 & $7 \cdot 5$ \\
\hline III & 1675 & $10 \cdot 7$ \\
\hline IV & 2216 & $14 \cdot 3$ \\
\hline V & 748 & $15 \cdot 8$ \\
\hline $\mathrm{x}$ & 290 & $16 \cdot 6$ \\
\hline \multicolumn{3}{|l|}{ Marital status } \\
\hline Married & 4290 & $13 \cdot 5$ \\
\hline Not married & 2843 & $8 \cdot 6$ \\
\hline \multicolumn{3}{|c|}{ Daily consumption of fruits and vegetables } \\
\hline Yes & 2393 & $11 \cdot 6$ \\
\hline No & 4718 & $11 \cdot 5$ \\
\hline \multicolumn{3}{|l|}{ Physical activity } \\
\hline Active & 4409 & $9 \cdot 5$ \\
\hline Sedentary & 2653 & $14 \cdot 9$ \\
\hline \multicolumn{3}{|l|}{ Alcohol consumption } \\
\hline Non-drinker & 3522 & $13 \cdot 1$ \\
\hline Occasional drinker & 1484 & $8 \cdot 3$ \\
\hline Frequent drinker & 995 & $9 \cdot 5$ \\
\hline Daily drinker & 1146 & $12 \cdot 6$ \\
\hline \multicolumn{3}{|l|}{ Smoking } \\
\hline Non-smoker & 4005 & $11 \cdot 9$ \\
\hline Smoker & 1947 & $9 \cdot 4$ \\
\hline Ex-smoker & 1203 & $13 \cdot 9$ \\
\hline
\end{tabular}

( $\mathrm{OR}=0 \cdot 92 ; 95 \% \mathrm{CI} 0 \cdot 71,1 \cdot 18)$. Additional adjustment for variables related with lifestyle (model 3) did not substantially modify these results. By length of residence, in 
Table 3 Logistic regression models for obesity in the immigrant population, overall and by length of residence in Spain; sample comprised 7155 persons aged 18 years and over residing in the city of Madrid, who were was surveyed between November 2004 and May 2005

\begin{tabular}{|c|c|c|c|c|c|c|}
\hline & \multicolumn{2}{|c|}{ Model 1} & \multicolumn{2}{|c|}{ Model 2} & \multicolumn{2}{|c|}{ Model 3} \\
\hline & OR & $95 \% \mathrm{Cl}$ & OR & $95 \% \mathrm{Cl}$ & OR & $95 \% \mathrm{Cl}$ \\
\hline Spanish population & $1 \cdot 00$ & & 1.00 & & 1.00 & \\
\hline Immigrant population & $0 \cdot 74$ & $0.58,0.94$ & 0.92 & $0 \cdot 71,1 \cdot 18$ & $0 \cdot 88$ & $0.68,1 \cdot 14$ \\
\hline \multicolumn{7}{|l|}{ Length of residence } \\
\hline$<2$ years & 0.67 & $0 \cdot 27,1 \cdot 69$ & $1 \cdot 00$ & $0 \cdot 39,2 \cdot 54$ & 0.96 & $0 \cdot 38,2 \cdot 46$ \\
\hline $2-4$ years & $0 \cdot 73$ & $0.49,1.09$ & 0.94 & $0 \cdot 62,1 \cdot 43$ & $0 \cdot 89$ & $0.58,1.36$ \\
\hline $5-9$ years & 0.81 & $0 \cdot 54,1 \cdot 21$ & $1 \cdot 02$ & $0.67,1.56$ & 0.97 & $0.63,1.48$ \\
\hline$\geq 10$ years & 0.69 & $0 \cdot 44,1 \cdot 06$ & 0.79 & $0.51,1 \cdot 23$ & 0.79 & $0.51,1 \cdot 23$ \\
\hline
\end{tabular}

Model 1, crude model; Model 2, adjusted for age, sex, social class and perceived health; Model 3, additionally adjusted for physical activity, fruit and vegetable consumption, smoking and alcohol consumption.

relation to the Spanish population, the crude OR was less than 1 in all groups, and became closer to 1 with increasing length of residence in Spain $(\mathrm{OR}=0.67,0.73$ and $0 \cdot 81$ in immigrants with less than 2, 2-4 and 5-9 years of residence, respectively), up to 10 or more years of residence $(O R=0 \cdot 69)$. The magnitude of this association, which did not reach statistical significance in any of the age groups, was considerably reduced after adjusting for sociodemographic variables and perceived health, but was not further modified after additional adjustment for lifestyle variables.

To test whether the study association varied by country of origin, we built interaction terms as the product of length of residence by country of origin, and we used likelihood ratio tests to compare models with interaction terms and without. Interactions did not achieve statistical significance $(P>0 \cdot 05)$. Additionally, we repeated the analyses only among immigrants from Latin American countries (who made up $65 \%$ of immigrants in our study), and again no association was observed.

\section{Discussion}

Our results show a lower frequency of obesity in immigrants residing in the city of Madrid in comparison to the Spanish population. Although a rising trend in the frequency of obesity was detected in the whole immigrant group with increasing length of residence in Spain up to 10 years, at which time the frequency decreased, these differences disappeared after adjusting for sociodemographic variables and health status, and were unchanged after additional adjustment for lifestyle variables. This lack of effect stands in contrast to the results consistently observed in North American studies. Two studies in US immigrants from different ethnic backgrounds showed a positive effect of length of residence on obesity ${ }^{(7,8)}$. In one of these studies this effect was not clearly discernible until 10 years of residence, with the frequency of obesity in immigrants - which was initially higher than in the native population - becoming practically the same after 15 years of residence ${ }^{(8)}$. This positive association between length of residence and frequency of obesity has also been observed in the USA in immigrants from Asian ${ }^{(6)}$ and Hispanic ${ }^{(1-5)}$ countries. The same positive association has consistently been found in studies in Canada ${ }^{(9-11)}$

The results of the few studies conducted in Europe are less consistent. Lahmann et al. found a negative effect of length of residence of immigrants in Sweden on the frequency of central obesity, measured by waist circumference $^{(15)}$. The same study, however, found a positive effect of length of residence in women when the indicator of obesity was percentage of body fat estimated by tetrapolar bioelectrical impedance. Other studies in Sweden ${ }^{(14)}$ and Amsterdam ${ }^{(16)}$ showed some positive effect of length of residence on obesity, but the effect was small and was seen only in immigrants from certain countries. For example, in the Amsterdam study, length of residence in Holland was associated with obesity in immigrants from Morocco but not in those from Turkey ${ }^{(16)}$.

The reasons for the positive effect of length of residence on obesity in immigrants are related to acculturation, a process by which immigrants progressively adopt behaviours and habits typical of the host country. If particular obesity factors associated with eating (e.g. a high-energy-density diet or one with a high glycaemic index) and physical activity (tendency to sedentarism) are frequent in the host country, the adaptation of immigrants would imply, in some measure, the adoption of these behaviours. Nevertheless, inconsistencies between studies in North America and those in Europe may indicate that immigrant acculturation varies by geographic and cultural setting. There are no studies on the influence of length of residence of immigrants on obesity in Southern Europe; therefore the absence of an association in our study is an important finding.

The lack of association in our work could mean that the behaviours of immigrants on arriving in Spain do not favour the development of obesity. In particular, the frequency of sedentarism in immigrants decreased with increasing length of residence in Spain, which would suggest that acculturation has a protective effect on obesity in migrants to Madrid. Furthermore, even though 
the immigration process may involve dietary changes that may be harmful to health (greater consumption of processed foods with higher energy density and higher glycaemic index), these changes and their effect on behaviour have also been seen to vary among immigrant populations and among host countries ${ }^{(19)}$. For example, another study has shown that increasing length of residence in Madrid immigrants, especially those from Morocco, is associated with greater consumption of milk products, vegetables, fish and legumes ${ }^{(20)}$. This could explain our finding of an absence of effect of length of residence on obesity. It has recently been found, perhaps partly as a consequence of these favourable changes in diet and physical activity, that South American and North African immigrants in the region of Madrid have lower cardiovascular and ischaemic heart disease mortality than the native population ${ }^{(21)}$.

On the other hand, we do not know how long it takes for immigrants to adapt and assimilate certain behaviours in the host country. With regard to behaviours that favour obesity, some studies have shown that the positive effect of length of residence on obesity in immigrants was seen clearly only after 15 years, and especially after 20 years of residence in the host country ${ }^{(2,3,10)}$. Our results, although they basically indicate the lack of effect of length of residence, would point in the opposite direction: the frequency of obesity in immigrants who had been in Spain for 10 years or more was lower than those with a shorter period of residence. This suggests that the acculturation of immigrants in Madrid may have a beneficial effect, in the long term, on the risk of developing obesity. However, other explanations must also be considered, such as a certain period effect in the immigration process that would condition the risk of obesity in immigrants at the time of arrival. Immigration is a relatively recent phenomenon in Southern European countries as opposed to those in Northern Europe and North America. Given the important process of urbanisation experienced by many developing countries, persons who have emigrated in more recent years may come from countries with a high prevalence of obesity and a high exposure to its determinants, especially those related to diet and physical activity; therefore the immigration process would not involve an overexposure to obesity factors. This could have occurred in the immigrant population we studied in the city of Madrid, most of whom came from Latin American countries where rapid transition is taking place in terms of nutrition, with a progressive increase in the frequency of obesity due to changes in diet and physical activity which are very similar to those observed in Western countries ${ }^{(22,23)}$.

Another reason for the absence of an association between length of residence and obesity in Madrid immigrants may be the urban nature of the population studied. The process of acculturation in immigrants depends on the density of the immigrant population in the host areas. Neighbourhood clustering of immigrant groups, a typically urban phenomenon, may make it easier to maintain the habits and behaviours of the country of origin ${ }^{(11)}$. If acculturation involves an overexposure to obesity factors, as some studies suggest ${ }^{(4,10)}$, living in neighbourhoods with a high density of immigrants would reduce the risk of obesity. Nevertheless, we believe that our results are not due to the urban character of the study population. On the one hand, the absence of an association between length of residence and obesity in Madrid immigrants, in opposition to what has been found in Northern American studies, might be due to factors that, although not well characterised, operate in Southern Europe. These factors might also explain geographic and cultural differences in certain eating behaviours and their relationship with obesity. For example, eating out, which has consistently been associated with obesity in US studies ${ }^{(24,25)}$, does not seem to exert any effect on obesity in the Spanish adult population ${ }^{(26)}$.

The variability of the results found in different studies shows the complex interactions among factors (biological or otherwise) present in immigrants before their arrival to the host country and among certain environmental factors to which they are exposed in the immigration process. The fact that some studies have found that, independently of length of residence, both ethnic group ${ }^{(11)}$ and country of origin ${ }^{(16)}$ affect obesity in immigrants shows the importance of factors present in immigrants before their arrival to the host country. The high level of exposure to obesity factors in immigrants arriving in the city of Madrid in recent years may reduce the potential impact on BMI of related environmental factors encountered on arrival.

To interpret our results correctly, certain methodological comments are in order. First, the causal inference is limited because this was a cross-sectional study. Second, factors related to diet and nutrition have not been adequately considered. Adjusting for variables associated with diet could have produced an overadjustment, since some dietary habits could be mediators of the association between length of residence and obesity. In fact, the models were adjusted for physical activity and consumption of fruits and vegetables, and a certain overadjustment may have resulted. In any case, the absence of an effect of length of residence on obesity was already seen after adjusting only for age and perceived health of the immigrants. Third, the measure of obesity used could have conditioned the results. The relationship between BMI and percentage of body fat has been reported to vary by ethnic group ${ }^{(27)}$. Moreover, we used self-reported height and weight, which is known to underestimate the prevalence of obesity; if this underestimate varied between immigrants and non-immigrants our results could be biased. However, the only study that has compared the validity of self-reported weight and height among immigrants and non-immigrants, in a population of Mexican origin, did not find differences between the 
two groups ${ }^{(28)}$. Another recent study compared the prevalence of obesity obtained by measuring height and weight with that obtained using self-reported height and weight, and no differences were found among the different ethnic groups ${ }^{(29)}$. Nor did an earlier study find significant differences between blacks and whites ${ }^{(30)}$.

In conclusion, the length of residence of immigrants in the city of Madrid is not associated with the frequency of obesity. It may be that the circumstances encountered by immigrants on arriving in Spain do not represent an overexposure to factors favouring obesity, relative to those they bring with them.

\section{Acknowledgements}

The study was supported by FIS grant 06/0366. The funding body had no role in data extraction and analysis, writing of the manuscript, or in the decision to submit the paper for publication. There are no conflicts of interest. J.L.G.-F. designed the study and coordinated the writing of the article. A.M.-G. contributed to the analysis of the study and to the drafting of the paper. E.R., P.G.-C., J.R.B. and F.R.-A. contributed to the interpretation of the results and to the drafting of the paper. All authors contributed to the final version of the article.

\section{References}

1. Kaplan MS, Huguet N, Newsom JT et al. (2004) The association between length of residence and obesity among Hispanic immigrants. Am J Prev Med 27, 323-326.

2. Barcenas CH, Wilkinson AV, Strom SS et al. (2007) Birthplace, years of residence in the United States, and obesity among Mexican-American adults. Obesity 15, 1043-1052.

3. Himmelgreen DA, Pérez-Escamilla R, Martinez D et al. (2004) The longer you stay, the bigger you get: length of time and language use in the US are associated with obesity among Puerto Rican women. Am J Phys Anthropol 125, 90-96.

4. Wolin KY, Colangelo LA, Chiu BC et al. (2009) Obesity and immigration among Latina women. J Immigr Minor Health 11, 428-431.

5. Fuentes-Afflick E \& Hessol N (2008) Acculturation and body mass among Latina women. $J$ Womens Health 17, $67-73$.

6. Lauderdale DS \& Rathouz PJ (2000) Body mass index in a US national sample of Asian Americans: effects of nativity, years since immigration and socioeconomic status. Int $J$ Obes Relat Metab Disord 24, 1188-1194.

7. Koya DL \& Egede LE (2007) Association between length of residence and cardiovascular disease risk factors among an ethnically diverse group of United States immigrants. J Gen Intern Med 22, 841-846.

8. Goel MS, McCarthy EP, Phillips RS et al. (2007) Obesity among US immigrant subgroups by duration of residence. JAMA 292, 2860-2867.

9. Cairney J \& Ostbye T (1999) Time since immigration and excess body weight. Can J Public Health 90, 120-124.

10. McDonald JT \& Kennedy S (2005) Is immigration associated with unhealthy weight gain? Overweight and obesity among Canada's immigrants. Soc Sci Med 61, 2469-2481.
11. Tremblay MS, Pérez CE, Ardem C et al. (2005) Obesity, overweight and ethnicity. Health Rep 16, 23-34.

12. Gordon-Larsen P, Harris KM, Ward DS et al. (2003) Acculturation and overweight-related behaviours among Hispanic immigrants to the US: the National Longitudinal Study of Adolescent Health. Soc Sci Med 57, 2023-2034.

13. Bates LM, Acevedo-García D, Alegría M et al. (2007) Immigration and generational trends in body mass index and obesity in the United States: results of the national Latino and Asian American Survey, 2002-2003. Am J Public Health 97, 70-77.

14. Lindström M \& Sundquist K (2005) The impact of country of birth and time in Sweden on overweight and obesity: a population based study. Scand J Public Health 33, 276-284.

15. Lahmann PH, Lissner L, Gullberg B et al. (2000) Differences in body fat and central adiposity between Swedes and European immigrants: the Malmö Diet and Cancer Study. Obes Res 8, 620-631.

16. Dijkshoorn H, Nierkens V \& Nicolau M (2008) Risk groups for overweight and obesity among Turkish and Moroccan migrants in The Netherlands. Public Health 122, 625-630.

17. Lanzieri G\& Corsini V (2006) First demographic estimates for 2005. Statistics in focus - Population and social conditions - 1/2006. http://epp.eurostat.ec.europa.eu/ cache/ITY_OFFPUB/KS-NK-06-001/EN/KS-NK-06-001-EN. PDF (accessed June 2009).

18. Gutiérrez-Fisac JL, Royo-Bordonada MA \& RodríguezArtalejo F (2006) Health risks associated with Western diet and sedentariness: the obesity epidemia. Gac Sanit 20, Suppl. 1, 48-54.

19. Gilbert PA \& Khokhar S (2008) Changing dietary habits of ethnic groups in Europe and implications for health. Nutr Rev 66, 203-215.

20. Montoya Saez PP, Torres Cantero AM \& Torija Isasa ME (2001) Nutrition among Moroccan immigrants in the community of Madrid: factors affecting the choice of food. Aten Primaria 27, 264-270.

21. Regidor E, De La Fuente L, Martínez D et al. (2008) Heterogeneity in cause-specific mortality according to birthplace in immigrant men residing in Madrid, Spain. Ann Epidemiol 18, 605-613.

22. Uauy R, Albala C \& Kain J (2001) Obesity trends in Latin America: transiting from under- to overweight. J Nutr $\mathbf{1 3 1}$, 893S-899S.

23. Kain J, Vio F \& Albala C (2003) Obesity trends and determinant factors in Latin America. Cad Saude Publica 19, Suppl. 1, S77-S86.

24. McCrory MA, Fuss PJ, Hays NP et al. (1999) Overeating in America: association between restaurant food consumption and body fatness in healthy adult men and women ages 19 to 80. Obes Res 7, 564-571.

25. Kant AM \& Graubard BI (2004) Eating out in America, 1987-2000: trends and nutritional correlates. Prev Med 38, 243-249.

26. Marín-Guerrero AC, Gutiérrez-Fisac JL, Guallar-Castillón P et al. (2008) Eating behaviours and obesity in the adult population of Spain. Br J Nutr 100, 1142-1148.

27. Rush EC, Goedecke JH, Jennings C et al. (2007) BMI, fat and muscle differences in urban women of five ethnicities from two countries. Int J Obes (Lond) 31, 1232-1239.

28. Lee SK (2005) Validity of self-reported weight and height: comparison between immigrant and non-immigrant Mexican Americans in NHANES III. J Immigr Health 7, 127-131.

29. Yun S, Zhu B-P, Black W et al. (2006) A comparison of national estimates of obesity prevalence from the behavioural risk factor surveillance system and the National Health and Nutrition Examination Survey. Int J Obes (Lond) 30, 164-170.

30. Nieto-García FJ, Bush TL \& Keyl PM (1990) Body mass definitions of obesity: sensitivity and specificity using selfreported weight and height. Epidemiology 1, 146-152. 